\title{
Family-Centered Preventive Intervention for Military Families: Implications for Implementation Science
}

\author{
William Beardslee • Patricia Lester • Lee Klosinski • \\ William Saltzman • Kirsten Woodward • William Nash • \\ Catherine Mogil • Robert Koffman • Gregory Leskin
}

Published online: 15 July 2011

(C) Society for Prevention Research 2011

\begin{abstract}
In this paper, we report on the development and dissemination of a preventive intervention, Families OverComing Under Stress (FOCUS), an eight-session familycentered intervention for families facing the impact of wartime deployments. Specific attention is given to the challenges of rapidly deploying a prevention program across diverse sites, as well as to key elements of implementation success. FOCUS, developed by a UCLAHarvard team, was disseminated through a large-scale demonstration project funded by the United States Bureau of Navy Medicine and Surgery (BUMED) beginning in 2008 at 7 installations and expanding to 14 installations by 2010. Data are presented to describe the range of services
\end{abstract}

\author{
W. Beardslee $(\bowtie)$ \\ Children's Hospital Boston, Harvard Medical School, \\ 21 Autumn Street, Suite 130.2, \\ Boston, MA 02215, USA \\ e-mail: william.beardslee@childrens.harvard.edu
}

P. Lester • L. Klosinski • W. Saltzman • C. Mogil • G. Leskin UCLA Semel Institute for Neuroscience and Human Behavior, 760 Westwood Plaza, Room A8-159,

Los Angeles, CA 90024, USA

\section{K. Woodward}

United States Bureau of Navy Medicine and Surgery,

2300 E Street, NW Bldg. \#6,

Washington, DC 20372-5300, USA

\section{W. Nash}

Department of Psychiatry, VA San Diego Healthcare System, UCSD,

3350 La Jolla Village Drive,

San Diego, CA 92161, USA

\section{R. Koffman}

National Intrepid Center of Excellence,

8901 Wisconsin Blvd,

Bethesda, MD 20889-5600, USA offered, as well as initial intervention outcomes. It proved possible to develop the intervention rapidly and to deploy it consistently and effectively.

Keywords Preventive intervention $\cdot$ Resilience $\cdot$ Military families Combat operational stress

\section{Introduction}

The recent Institute of Medicine (IOM) report reviewed evidence for prevention and promotion strategies for children and families (National Research Council and Institute of Medicine [NRCIOM] 2009), detailing developments in the field since the last report (NRCIOM 1994). Both in the IOM report (NRCIOM 2009) and in other commentaries (Proctor et al. 2002), there has been a call for greater study of how to implement and disseminate programs widely and effectively. The sustained operational tempo in Iraq and Afghanistan created an urgent national need to support military readiness by enhancing family resilience and provided an opportunity to test a new model of intervention development and dissemination.

About one million service members, approximately $43 \%$ of all military personnel, are parents (Office of the Deputy under Secretary of Defense 2007). Throughout wartime deployments, these families face many stressors, including repeated relocation, parental absence, and fears and concerns (Palmer 2008; Segal 1986). Several earlier studies suggest that military children typically exhibit resilience and wellbeing, despite these stressors (Cozza et al. 2005; Jensen et al. 1996). However, more current studies indicate increased child distress during parental deployment (Chartrand et al. 2008; Flake et al. 2009), risk for child maltreatment (McCarroll et al. 2000), and cumulative risk of deployment 
separation on adolescent emotional adjustment (Chandra et al. 2010). As a part of our team's intervention development strategy, we conducted an assessment of the effects of deployments on families, which suggested that parental combat deployments have an impact that lasts beyond the duration of deployment and is associated with outcomes in children, predicted both by the length of deployment and the level of parental psychological distress (Lester et al. 2010b).

Furthermore, across a variety of intervention strategies, there has been strong endorsement for structured manualbased programs that enhance parenting and parent-child relationships (NRCIOM 2009; Sandler et al. 2010). A central tenant of developmental research is that effective caregiverchild relationships provide an essential framework for building child adaptive skills, including emotional and behavioral self-regulation (Nachmias et al. 1996; Rutter and Quinton 1984; Sroufe et al. 2005). Interventions that promote adaptive skills and behaviors in children and parents, particularly those that enhance parent-child communication, bonding, and family management, reduce problem behaviors and emotional distress in children throughout development (Feinberg and Kan 2008; Spoth et al. 2002). Given that military families have many existing strengths and that family factors play a central role in mediating childhood stress, it seemed prudent to design an intervention that built on these strengths, yet further enhanced protective family processes, particularly in light of the repeated deployments of the current conflicts.

FOCUS (Families OverComing Under Stress) was specifically developed as a family-centered preventive intervention strategy adapted for the needs of military families facing the stressors of multiple deployments. Strength-based approaches with families have a particularly strong evidence base (Beardslee and Knitzer 2003; NRCIOM 2009); therefore, the concept of resilience, which focuses on positive adaptation in the face of significant adversity, was central to FOCUS. Early conceptions of resilience focused on the role of individual traits contributing to childhood hardiness or "invulnerability" (Rutter 1985). Subsequent longitudinal studies that permitted more in-depth analyses of resilient processes highlighted the importance of attachment relationships as predictors of child resilience when exposed to hardship, trauma, or loss, the importance of families, and the need to understand the broader ecological context surrounding the child (Sroufe 2005; Werner 1993). In particular, children's outcomes in the face of adverse events were significantly mediated by the quality of parenting and the caregiving environment (Masten 2004).

\section{Chronology of Intervention Development}

Given the urgent national need for a rapid, scalable framework of preventive services for military families, our military partners requested that FOCUS be developed and implemented without first conducting a randomized trial. Instead FOCUS was developed by adapting and consolidating key aspects of existing strength- and evidence-based interventions utilized in comparable contexts. From the beginning, FOCUS was conceived to be a trauma-informed, skill-based, family-centered prevention (selective and indicated) intervention designed to promote family resiliency and to mitigate the sequelae of highly stressful deploymentrelated events on children and parents. The early development of FOCUS was facilitated by collaboration between its developers at the UCLA Semel Institute/Children's Hospital, Harvard University and the National Child Traumatic Stress Network (NCTSN), and was supported through funding from the Frederick R. Weisman Philanthropic Foundation. In order to meet the needs of the greatest number of military families, FOCUS was designed to be highly scalable. Additionally, the intervention had to be straightforward to deliver; only approaches that could be taught to a wide range of providers in a variety of settings could be considered. Finally, it needed to be highly portable and flexible so it could be quickly disseminated to a variety of very different communities, geographies, family types, and military service requirements.

The three foundational programs from which FOCUS was developed all had a family-level, rather than an individual-level, perspective. They were all directed toward children and parents who were at risk for mental disorders or serious life impairment, and yet none were conceived to provide treatment for a mental disorder. They were selective or indicated preventive interventions, as defined by the IOM Committee on Prevention of Mental Disorders (Mrazek and Haggerty 1994) and endorsed by the recent IOM prevention report (2009).

The first intervention, Project TALK (Teens and Adults Learning to Communicate), is a manualized, familycentered, prevention intervention developed to promote positive psychological adjustment in adolescents affected by parental illness (Lester et al. 2008; Rotheram-Borus et al. 2001, 2004, 2006). Project TALK contributed a proven model for a modularized prevention intervention, as well as the implementation of cognitive-behavioral skills delivered in a prevention framework across the family system. Additionally, Project TALK informed FOCUS developers regarding risk and protective factors operating in stressed families (Lester et al. 2003, 2010c). The second preventive intervention strategy on which FOCUS was founded was the UCLA Trauma-Grief Intervention, a school-based, trauma-focused, cognitive-behavioral therapy program developed in post-war Bosnia for children and parents exposed to trauma and loss in war zones and other violent community settings (Layne et al. 2001). FOCUS incorporated from this intervention core elements of trauma- 
informed psychoeducation and skill-building techniques. Family Talk, the third foundational component of FOCUS, is a brief, family-based preventive intervention that addresses obstacles to communication and the lack of attention to parenting common in families affected by parental depression (Beardslee et al. 2003, 2007; Beardslee and Gladstone 2001; D'Angelo et al. 2009). The Family Talk intervention contributed to FOCUS a systematic approach to sharing a family narrative, as well as practical strategies to building resilience.

Crucial to intervention uptake, the FOCUS framework was then integrated with the military's public health model for operational stress in which service members were already being instructed. The central prevention and resiliency framework being developed in the U.S. Navy (USN) and U.S. Marine Corps (USMC) concurrently with FOCUS - and which informed implementation of FOCUS - is the Stress Continuum Model, a destigmatizing heuristic for recognizing significant but preclinical levels of distress and functional impairment in service members and their spouses and children (Nash 2011). The Stress Continuum Model and an early intervention model, Combat and Operational Stress First Aid, have been disseminated as the core of organization-wide, leader-directed Combat and Operational Stress Control (COSC) efforts (U.S. Marine Corps \& U.S. Navy 2010). FOCUS incorporated the COSC Model into its assessment components, promoting a classification of family and family-member strengths and vulnerabilities according to their severity and relative need for interventions. FOCUS also utilizes the language of the COSC Model in its psychoeducational components and skill-building exercises.

An initial FOCUS manual integrating elements from the source interventions and the COSC model, as well as a set of key informant interviews, family focus groups, and environmental and systems assessment, was finalized in 2007 (Saltzman et al. 2007) after piloting with USMC families at Camp Pendleton, California during the early years of the Afghanistan and Iraq wars (Saltzman et al. 2009). In 2008, the Navy Bureau of Medicine and Surgery (BUMED) funded FOCUS as a service program for selected USN and USMC installations through a contract with the UCLA Semel Institute Intervention Team.

Individual Family Resiliency Training (IFRT) Central to the FOCUS intervention is IFRT, an eight-session resiliency training program for parents and children. IFRT includes a family assessment completed online with real-time feedback immediately available to the intervention provider (referred to in FOCUS as a Resiliency Trainer). During initial sessions, the Resiliency Trainers provide family members with education about the impact of combat operational stress and deployment in terms that are developmentally relevant to the family. Throughout training, there is a focus on shared family-level skills across the deployment cycle: communication, goal setting, problem solving, emotion regulation, and managing combat/deployment reminders. The eight sessions of the FOCUS intervention are structured to include three phases, as described in Fig. 1: (1) Narrative Construction: initial sessions with the parents alone, to collect a family history and to begin constructing a narrative of deployments, and two sessions with the children, apart from the parents, to construct ageappropriate narratives of deployments and other family challenges; this phase helps family members reflect on their experiences and reactions, appreciate differences in reactions across the family, bridge estrangements and develop a familylevel sense of meaning. (2) Parent Planning: one or two sessions with the parents, apart from children, to prepare them for a leadership role in the family sessions, including promoting appropriate sharing of narratives, identification of effective strategies for addressing children's concerns, and practice of core skills that can be used at home or during family sessions; and (3) Narrative Sharing and Skill Practice: two to three sessions to share the family's deployment narratives, construct meaning of their experiences, practice newly acquired skills, and plan for the future. Detailed descriptions of the intervention skills and goals have been reported previously (Lester et al. 2010a, 2011a).

Prevention as a "Suite of Services" In initial planning with military partners, it was clear that a continuum of approaches would be most effective at reaching the largest number of military families. Consistent with a public health approach described by Wingood and DiClemente (2006), FOCUS developed a "suite of services," each of which provided the core IFRT psychoeducation and skills, but at different levels of intensity, moving from universal to indicated prevention services (Fig. 2). For outreach and educational purposes, FOCUS trainers provided briefings and trainings to base command, community, and base service providers, and to take part in large-scale briefings for service members and their families. Moreover, FOCUS staff were embedded in the overall framework of care and could respond to the needs of the military community. For example, if a death in combat or a large mobilization occurred, FOCUS staff responded via appropriate expertbased workshops to families or larger group briefings (i.e., grief, trauma, reintegration, deployment) conducted in coordination with other systems of care. For service members, children, and families who were not able or ready to participate in the full IFRT program, single-session skill-based workshops and consultations were offered. These broader-based services were especially important during the start-up of each site and often served as gateways for families to enter the eight-session IFRT program. As the unique needs of families with very young children, couples, and the wounded, ill, and injured 
Fig. 1 Individual Family

Resiliency Training

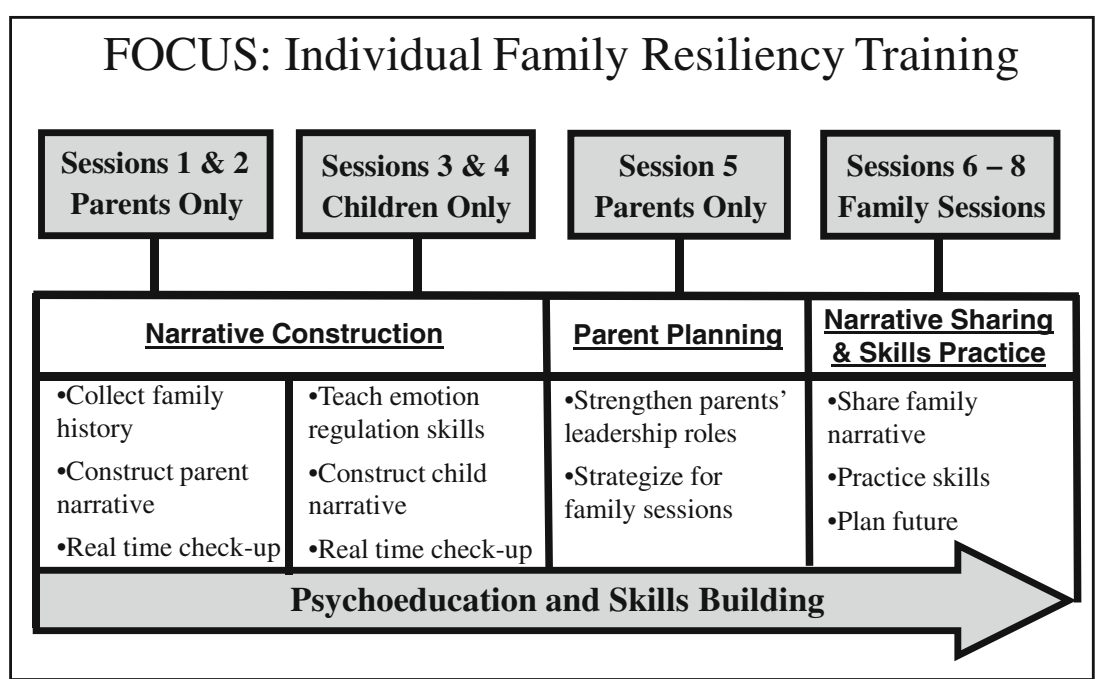

population were identified, further adaptations of IFRT were developed. The suite of services was found to be particularly useful for military families who needed help quickly before or after deployment and whose time and resource constraints required a flexible or modular format.

Intervention Implementation

Site Selection In the first year, BUMED selected nine USN and USMC sites for program implementation. Selection criteria included the number of attached families, number of unit deployments, and degree of service members' combat exposure. There was considerable site variability, ranging from relatively small installations with around 4,000 active duty personnel to much larger bases, the largest of which had more than 40,000 active duty service members. In the second year of service, five additional USN and USMC installations were added, including the USMC Wounded Warrior Regiment. Additionally, a pilot, which expanded services to U.S. Army and Air Force installations, was added during the second year.

Personnel Selection and Training A key to successful program implementation was hiring FOCUS site staff

Fig. 2 FOCUS suite of services

\section{FOCUS Suite of Services:}

\section{Public Health Strategy for Implementation}
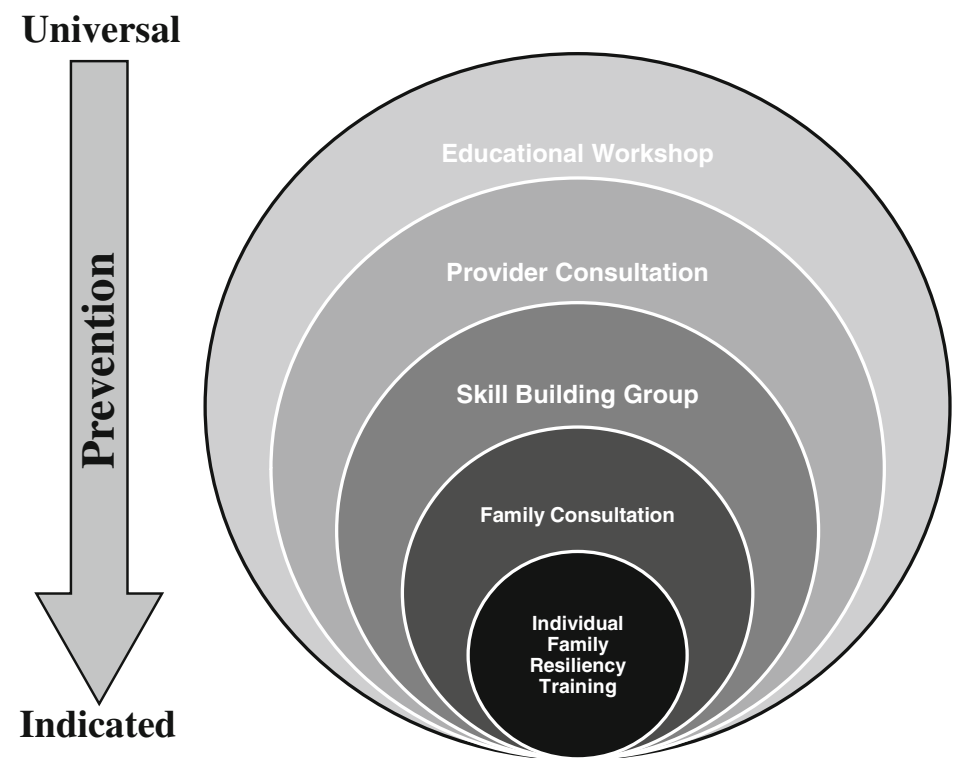
members who embodied the highest levels of professional expertise along with an entrepreneurial spirit that was necessary to "stand up" a new service within a complex and competitive service market. Full-time resident teams consisting of a Site Director to manage the local site, one to four Resiliency Trainers, and administrative support were hired after being interviewed using standardized guides. Whenever possible, military spouses or retired service members were recruited, which provided FOCUS with key insights into the community and which helped with building alliances. Furthermore, Site Directors and Resiliency Trainers had to be excellent clinicians - doctoral or master's level mental health practitioners - with a background in child and family psychology. This was critical, as FOCUS staff had to implement a manualized program with fidelity while exercising sufficient clinical judgment to customize the intervention for the unique needs of military families.

In order to quickly train new FOCUS staff, an 80-hour on-line training was paired with a full week of in-person training that drew upon case material, role play, skill practice, and personal reflection. The on-line training provided important content areas including military culture, combat and operational stress, child traumatic stress, child development, post-traumatic stress disorder/traumatic brain injury (PTSD/TBI), and administrative functions. In-person training allowed for demonstration and practice of FOCUS sessions and core skills. To prepare staff to work with their local communities, the training described differences between and within each service branch and included material about the specific military installations, differences in deployment experiences and cycles, and community norms and values. The shared training experience led to a strong esprit de corps and provided a basis for ongoing dialogue. Central to the training strategy was provision of core supervisory support both as-needed and on a regular basis, as well as continued training relevant to emerging science, community issues, and quality improvement data. In addition to ensuring effective intervention delivery, FOCUS supervisors were consulted to problem-solve about such implementation matters as finding office space, building relationships, and networking. Supervision was also implemented through an on-line "learning community" model, which integrated lessons learned across sites and provided a virtual community for addressing model implementation issues and identifying training needs.

Program Outreach and Engagement Given that FOCUS was a new program entering into an existing continuum of care for military families, considerable thought was given to avoiding issues of territoriality while becoming a working member of the base community. The first step towards that goal was to embed FOCUS services within the military structure by physically locating them on military installations. Led by BUMED, FOCUS staff employed a strategy of first securing support from the local command at each base, identifying a lead point of contact with a central position within the base service community, and then actively outreaching to all stakeholders and potential gatekeepers within the base and surrounding community. This included the leadership and staff of family support services, base medical facilities, schools, chaplains, as well as other military preventive and support programs.

To further spread the word, FOCUS staff members participated in pre- and post-deployment briefings; wrote columns in base newspapers and public service announcements; and provided consultations, workshops and trainings for parents and children and community service providers. Outreach, partnership building, and program promotion occupied a significant portion of FOCUS staff time, especially during each site's first year of operation. Engagement strategies had to be customized for each base, as there were significant differences in the cultures and community structures of Marine, Navy, Army and Air Force installations. Even after a period of initial intense program promotion, outreach remained key to FOCUS success. Site Directors typically spent approximately 50\% of their time doing outreach, $25 \%$ delivering services, and $25 \%$ managing the site. Resiliency Trainers settled into a pattern of providing services for $75 \%$ of their time and conducting briefs for the remainder.

Framing and Positioning of Services Recognizing the reluctance of many military personnel to seek mental health services, the overall aim was to make this prevention model available in a confidential and non-stigmatizing manner. To enhance family engagement, FOCUS was not implemented as a mental health treatment, but as a non-clinical resiliency training program developed with an educational preventive curriculum. Participation in the intervention was not noted in the medical or service records of participating service members or their families. FOCUS providers were formally designated as "Resiliency Trainers" to avoid clinical connotation and to promote family resiliency as a component of training and preparation for deployment. The program focused on identifying strengths and enhancing family resilience through skill development and structured in-session experiences and practice at home. Whenever possible, this framing was supported by locating FOCUS offices away from medical and mental health service sites, offering family-friendly hours on evenings and weekends, and decorating the meeting rooms in a colorful and non-institutional fashion.

Data Management Leveraging the technology infrastructure of the UCLA Semel Institute and NCTSN, we were able to simultaneously build and deliver an extensive data management system. The IT platform provided multiple levels of technology 
support for rapid implementation, including real-time family assessment, program website and on-line interactive family resiliency training, basic and advanced trainings through an on-line learning center, and specific Internet-based tools customized for FOCUS. An innovative Internet-based cloud data management system (described previously in Lester et al. 2010a) has been used for program management, implementation, and evaluation.

Evaluation Strategy Evaluation efforts were focused on providing real-time assessment data for each family that could be used to immediately customize the intervention according to the family's specific needs and wishes, to track effectiveness of the program in key targeted domains, and to guide outreach efforts and further program refinement. To render the family's assessment data immediately useful to the Resiliency Trainer and family, a color-coded flagging system consistent with the COSC Model was used; when family members filled out the measures on computers, their responses were automatically scored and a report provided with feedback on relative family strengths and ways in which the intervention should be customized.

This on-line family "check-up" assessed parent (service member and spouse report), child (parent report and child self-report) and family adjustment at time of entry into the program, as well as at program exit and follow-up, using standard, widely used measures where available. Specific domains assessed include parent and child psychological symptoms, general family functioning, loss and grief reactions, coping skills, and strengths/resiliency. An additional set of ratings measured each parent's satisfaction and perception of the impact of the FOCUS intervention. To evaluate the families' responses to FOCUS, we have examined the initial implementation results of IFRT completed with 488 families (742 parents and 873 children). Described previously in the American Journal of Public Health (Lester et al. 2011b), initial outcomes have demonstrated significant reductions in child emotional and behavioral distress, as well as statistically significant improvements in prosocial behaviors (Strengths and Difficulties Questionnaire; Goodman et al. 2000). Children participating in FOCUS reported significantly increased use of positive coping strategies, including dealing with stressful life events, problem solving, and emotion regulation (Kidcope; Spirito et al. 1988). Significant reductions in both service member and civilian parent psychological symptoms through assessment of change scores and prevalence rates were found on the Brief Symptom Inventory (Derogatis 1993). Family functioning improved in the problem solving, communication, roles, affective responsiveness, and behavior control areas on the McMaster Family Assessment Device (Ryan et al. 2005). These were particularly important as they were specific dimensions targeted by resiliency training. Furthermore, ratings of program satisfac- tion were very high, and families reported positive perceptions of change for all key intervention domains.

Due to the FOCUS suite of services as well as community satisfaction, the intervention reaped a large number of families. Table 1 describes the range of activities and provides an account of participants in each activity. Table 2 provides statistics on the number of participants for the family resiliency training services for the same period of time, including both skill-building groups and IFRT. The large increase in Year 2 over Year 1 was due in part to more sites being involved, and by the beginning of Year 2, to all original sites being fully operational. While customized IFRT was a central facet of the service mission, it should be noted that a greater number of people engaged FOCUS through community briefings and educational workshops.

Families found their way to FOCUS through a variety of different pathways (Table 3). The greatest number of participants was self-referred, followed by referrals from schools, military social services, military health providers, and other military sources. This indicates both that families had an awareness of what they needed and that the military service systems supported FOCUS. Notably, it was not uncommon for some family members to need clinical intervention or other support service referrals; these were provided and tracked in order to support greater access to care for service members and their families (Table 4). The data on referrals emphasizes that FOCUS often provided a gateway to engaging individuals in other services and demonstrated how selective and indicated psychological health prevention services may fit into a continuum of care. Furthermore, the suite of services has ensured that FOCUS will be able to realign and integrate itself into a critical role in the evolving world of military family services.

\section{Discussion}

Recent work in prevention science has emphasized the need to adapt interventions flexibly to meet individual, family and community needs, and to build sustained relationships across the community. Supporting Wingood and DiClemente's (2006) application of Roger's (1983) characteristics of adoptable interventions, FOCUS strengths can be classified into five characteristics: (1) Complexity. We chose to develop and implement an intervention with low complexity that could be delivered by a wide range of personnel in various settings. (2) Relative advantage. In contrast to existing services, FOCUS was confidential, strength-based, and skills-oriented; congruent with the IOM approach to prevention, as well as the COSC model, FOCUS was implemented to address specific gaps in selective and indicated prevention services. (3) Compatibility. The FOCUS team's development 
Table 1 Participation in FOCUS services: community outreach and education

${ }^{a}$ March 10, 2008 through June 10,2009

b June 11, 2009 through June 10, 2010

\begin{tabular}{|c|c|c|c|c|c|c|}
\hline \multirow[t]{2}{*}{ Community outreach and education } & \multicolumn{3}{|l|}{ Events } & \multicolumn{3}{|c|}{ Attendees } \\
\hline & Year $1^{\mathrm{a}}$ & Year $2^{\mathrm{b}}$ & Total & Year 1 & Year 2 & Total \\
\hline Total Community Group Briefings & 339 & 515 & 854 & 17707 & 28458 & 46165 \\
\hline Provider Group Briefings & 179 & 270 & 449 & 3712 & 6667 & 10379 \\
\hline Indirect Outreach/Presentations & 225 & 507 & 732 & 22061 & 34240 & 56301 \\
\hline FOCUS Consultations & 207 & 406 & 613 & 781 & 1300 & 1581 \\
\hline FOCUS Educational Workshops & 52 & 372 & 424 & 1928 & 9707 & 11635 \\
\hline
\end{tabular}

of strong alliances with the leadership of Navy medicine, local command and providers, and military families guaranteed a tight, sustained feedback loop to promote respect, cultural compatibility, cultural responsiveness, and sustained consumer inputs. (4) Trialability. The FOCUS intervention underwent extensive quality improvement and modification based both on service delivery experience and on data generated by families. (5) Observability. The real-time assessments confirmed readily observable positive outcomes, verified by families' indications of child and family improvement.

An important lesson from the initial demonstration project included the need to distinguish FOCUS services from existing universal prevention programs, as well as from clinical treatment. Educating communities, providers, and families about the relevance of more intensive prevention in the context of wartime deployments was also central to the implementation process. Equally important was that the full eight-session intervention was developed before other FOCUS services. This in-depth work helped us understand what military families generally needed. Doing the full intervention highlighted a set of core components and key characteristics and strategies that we were then able to use in less intensive contexts such as individual consultations and single session group family skill-building exercises.

Not only did the intervention develop based on evolving needs and local issues, but so did the various kinds of partnerships and alliances. As FOCUS services became operational in the field, families, other service providers on the continuum, and leadership came to recognize the value of the intervention. Its uptake increased, and it became a regular part of the continuum of services offered. Thus, the alliances themselves evolved, and have continued to evolve as the program has expanded.

Limitations We recognize the limitations on the work brought about by the decision not to first conduct a randomized trial and to move to rapid deployment. Clearly, in many other circumstances, randomized trials provide the best data about how interventions work, and for whom they work or do not work. At the same time, there was sound randomized trial data from multiple trials of the source interventions. Similarly, we did not have the resources to have separate individuals conducting the implementation and dissemination process at each base, but rather relied on extensive case notes and interviews with FOCUS team members, military partners, and senior advisors. We acknowledge that a different kind of data would have been obtained had we had the resources and opportunity to study the process. More generally, we recognize that our data reporting may be subject to bias because we are relying on information from people who are delivering the interventions and supervising the work, as well as from our partners. We view this service demonstration project as an initial phase; notably, a randomized trial of FOCUS for combat injured service members and their families is currently in progress through the Uniformed University of the Health Sciences.

Research The IOM Prevention Report calls for much more study of the processes of implementation and dissemination. Further research (NRCIOM 2009) is especially needed on the

Table 2 Participation in FOCUS services: FOCUS resiliency training

\begin{tabular}{|c|c|c|c|c|c|c|c|}
\hline \multirow[t]{2}{*}{ FOCUS resiliency training } & \multicolumn{3}{|l|}{ Number } & & \multicolumn{3}{|c|}{ Attendees } \\
\hline & Year 1 & Year 2 & Total & & Year 1 & Year 2 & Total \\
\hline \multirow[t]{3}{*}{ FOCUS Family Skill-Building Groups } & \multirow[t]{3}{*}{173} & \multirow[t]{3}{*}{553} & \multirow[t]{3}{*}{726} & Adults & 691 & 1232 & 1923 \\
\hline & & & & Children & 894 & 2954 & 3848 \\
\hline & & & & Total & 1584 & 4186 & 5770 \\
\hline \multirow{3}{*}{$\begin{array}{l}\text { FOCUS Individual Family Resiliency } \\
\text { Training (IFRT) Enrollment }\end{array}$} & \multirow[t]{3}{*}{306} & \multirow[t]{3}{*}{581} & \multirow[t]{3}{*}{887} & Adults & 481 & 916 & 1397 \\
\hline & & & & Children & 575 & 990 & 1565 \\
\hline & & & & Total & 1056 & 1906 & 2962 \\
\hline
\end{tabular}


Table 3 Referral sources to FOCUS through June 2010

\begin{tabular}{lccc}
\hline Source of referrals & \multicolumn{3}{l}{ Percentage of referrals ${ }^{\mathrm{a}}$} \\
\cline { 2 - 4 } & $\begin{array}{l}\text { Year 1 } \\
(N=1302)\end{array}$ & $\begin{array}{l}\text { Year } 2 \\
(N=775)\end{array}$ & $\begin{array}{l}\text { Total } \\
(N=2745)\end{array}$ \\
\hline Workshops & $3 \%$ & $2 \%$ & $2 \%$ \\
Chaplain & $3 \%$ & $3 \%$ & $3 \%$ \\
Health Care Provider & $4 \%$ & $5 \%$ & $6 \%$ \\
Skill-Building Groups & $4 \%$ & $6 \%$ & $6 \%$ \\
Other & $11 \%$ & $8 \%$ & $9 \%$ \\
Military & $6 \%$ & $8 \%$ & $7 \%$ \\
Mental Health Provider & $8 \%$ & $8 \%$ & $8 \%$ \\
Military Social Services & NA & $14 \%$ & $13 \%$ \\
School & $18 \%$ & $10 \%$ & $11 \%$ \\
Self-Referred & $43 \%$ & $37 \%$ & $36 \%$ \\
\hline
\end{tabular}

${ }^{\mathrm{a}}$ Due to rounding, percentages may not sum to $100 \%$

process of rapidly developing and deploying interventions that strengthen families facing traumagenic events, including natural disasters and terrorist attacks. If possible, comparative designs - either random assignments with long-term followup or time series analyses - should be used both to evaluate the initial interventions and to examine the ecological contexts that make effective rapid deployment possible. Our experience with different military installations and service branches highlights the importance of understanding specific ecologic contexts in which interventions are delivered and of being able to flexibly adapt the core strategies to those contexts. Similarly, knowledge is sorely needed about organizational characteristics that enable interventions to incorporate effective family-based prevention services, as well as the most effective ways to disseminate interventions and provide resources to families. While in our own work it was not possible to employ a randomized design in this intervention and deployment cycle, we certainly believe that future research designs will provide more detailed study of the efficacy of core components of FOCUS.

\section{Future Directions for FOCUS}

Expansion of Services From the beginning, FOCUS was developed to be highly scalable in order to meet the needs of the large number of military families with children who experience multiple deployments. In addition to the uniformed services, there are other populations, such as Veterans, National Guard and Reservists, who may benefit from a family-centered preventive approach. Other settings for customized FOCUS services may include more intensive settings, such as the National Intrepid Center for Excellence, where families of warriors affected by traumatic brain injury and combat related mental health problems will be served.
Development of Web-Based Interactive Family Services We have developed a website (www.focusproject.org) with educational materials, as well as a portal to our interactive family resiliency training activity (FOCUS World), based on the FOCUS experience. FOCUS World provides military families with the opportunity to learn and practice key resiliency skills, build an on-line family deployment narrative, engage in real-time interactions with other family members, and download useful family tools and activities. The web-based program is designed to serve as a direct service to families living away from delivery sites, as well as to provide booster opportunities for families who have gone through FOCUS. These web-based services will increasingly become incorporated into the FOCUS intervention.

Future Intervention Development More broadly, much more attention needs to be given to a conceptual framework that describes methods for rapidly developing interventions by combining existing interventions or developing new approaches from existing ones. We believe that the FOCUS intervention was greatly strengthened by bringing together three different perspectives (medical illness, trauma, and depression/life adversity), as well as being integrated with the military public health model. Furthermore, although each of the foundational interventions has been widely used and has a strong evidence base, it is not realistic to think that interventions devised a decade ago meet the challenges faced today. We believe that much more attention needs to be paid to how established preventive interventions need to be changed and modified over time to meet the needs of different cultural groups, changing demographics, and

Table 4 Referral sources by FOCUS through June 2010

\begin{tabular}{lrr}
\hline Referral out & Number & Percentage \\
\hline Community Referrals & 3 & \\
Other & 6 & $0.54 \%$ \\
Healthcare Provider-Community & 10 & $1.08 \%$ \\
Health and Wellness Services & 12 & $1.80 \%$ \\
Additional FOCUS Services & 22 & $3.16 \%$ \\
Informational Resources-Community & 26 & $4.68 \%$ \\
Social Services-Community & 36 & $6.49 \%$ \\
School Services & 117 & $21.08 \%$ \\
Mental Health Provider-Community & & \\
Military Referrals & 12 & $2.16 \%$ \\
Chaplain & 15 & $2.70 \%$ \\
Military One Source & 21 & $3.78 \%$ \\
Informational Resources-Military & 22 & $3.96 \%$ \\
Healthcare Provider-Military & 103 & $18.56 \%$ \\
Mental Health Provider-Military & 150 & $27.03 \%$ \\
Social Services-Military & 555 & $100.00 \%$ \\
Total &
\end{tabular}


disease and illness patterns. We believe that doing this collaboratively with other intervention developers offers the best possibility for new intervention development.

\section{Conclusion}

It proved possible to rapidly develop and deploy an intervention that addressed an urgent unmet need. Basing the work on other related strength-based family preventive interventions; being able to deliver both the full intervention and distinct components in a suite of services to meet specific community, individual and family needs; having effective data management systems to allow the individualization of programs for families; paying strong attention to the alliance at both the leadership level and on the ground; and having a high quality staff with extensive support and a very strongly shared sense of mission; all contributed to this success and are likely to be applicable and necessary to other similar intervention situations.

Ours was a profoundly shared mission. Through our work, we came to have enormous admiration for the courage and remarkable strengths of service personnel and their families. The service members, their caregivers, and the families themselves became our partners both in intervention development and in understanding how to help other families. We are deeply grateful to them.

Acknowledgements The authors acknowledge the support of the Navy Bureau Medicine and Surgery (BUMED) for the implementation of FOCUS Project Resiliency Training Program for Military Families. They also acknowledge the strength, honor, commitment, and sacrifices made by military families on behalf of our country.

\section{References}

Beardslee, W. R., \& Gladstone, T. R. G. (2001). Prevention of childhood depression: Recent findings and future prospects. Biological Psychiatry, 49, 1101-1110.

Beardslee, W. R., \& Knitzer, J. (2003). Strengths-based family mental health services: A family systems approach. In K. Maton, C. Schellenbach, B. Leadbeater, \& A. Solarz (Eds.), Investing in children, youth, families, and communities: Strengths-based research and policy (pp. 157-171). Washington, DC: American Psychological Association.

Beardslee, W. R., Gladstone, T. R. G., Wright, E. J., \& Cooper, A. B. (2003). A family-based approach to the prevention of depressive symptoms in children at risk: Evidence of parental and child change. Pediatrics, 112, 119-131.

Beardslee, W. R., Wright, E. J., Gladstone, T. R. G., \& Forbes, P. (2007). Long-term effects from a randomized trial of two public health preventive interventions for parental depression. Journal of Family Psychology, 21, 703-713.

Chandra, A., Lara-Cinisomo, S., Jaycox, L. H., Tanielian, T., Burns, R. M., \& Ruder, T. (2010). Children on the homefront: The experience of children from military families. Pediatrics, 125 , $16-25$.

Chartrand, M. M., Frank, D. A., White, L. F., \& Shope, T. R. (2008). Effect of parents' wartime deployment on the behavior of young children in military families. Archives of Pediatrics \& Adolescent Medicine, 162, 1009-1014.

Cozza, S., Chun, R. S., \& Polo, J. A. (2005). Military families and children during operation Iraqi Freedom. Psychiatric Quarterly, 76, 371-378.

D’Angelo, E. J., Llerena-Quinn, R., Shapiro, R., Colon, F., Rodriguez, P., Gallagher, K., et al. (2009). Adaptation of the preventive intervention program for depression for use with predominantly low-income Latino families. Family Process, 48, 269-291.

Derogatis, L. R. (1993). BSI Brief Symptom Inventory: Administration, scoring, and procedure manual (4th ed.). Minneapolis, MN: National Computer Systems.

Feinberg, M. E., \& Kan, M. L. (2008). Establishing family foundations: Intervention effects on coparenting, parent/infant well-being, and parent-child relations. Journal of Family Psychology, 22, 253-263.

Flake, E. M., Davis, B. E., Johnson, P. L., \& Middleton, L. S. (2009). The psychosocial effects of deployment on military children. Journal of Developmental \& Behavioral Pediatrics, 30, 271-278.

Goodman, R., Ford, T., Simmons, H., Gatward, R., \& Meltzer, H. (2000). Using the Strengths and Difficulties Questionnaire (SDQ) to screen for child psychiatric disorders in a community sample. British Journal of Psychiatry, 177, 534-539.

Jensen, P., Martin, D., \& Watanabe, H. (1996). Children's response to parental separation during Operation Desert Storm. Journal of the American Academy of Child \& Adolescent Psychiatry, 35, 433-441.

Layne, C. M., Pynoos, R. S., Saltzman, W. R., Arslanagic, B., Black, M., Savjak, N., et al. (2001). Trauma/grief-focused group psychotherapy: School-based postwar intervention with traumatized Bosnian adolescents. Group Dynamics: Theory, research, and practice. Special issue: Group-based interventions for trauma survivors, 5, 277-290.

Lester, P., Stein, J. A., \& Bursch, B. (2003). Developmental risk for somatization in adolescents of parents with AIDS. Journal of Developmental and Behavioral Pediatrics, 24, 242-250.

Lester, P., Rotheram-Borus, M. J., Elia, C., Elkavich, A., \& Rice, E. (2008). TALK: Teens and adults learning to communicate. In C. W. LeCroy (Ed.), Evidence-based treatment manuals for children and adolescents (pp. 170-285). New York: Oxford University Press.

Lester, P., Leskin, G., Woodward, K., Saltzman, W., Nash, W., Mogil, C., et al. (2010a). Wartime deployment and military children: Applying prevention science to enhance family resilience. In S. MacDermid-Wadsworth \& D. Riggs (Eds.), Risk and resilience in U.S. military families (pp. 149-173). New York: Springer Science + Business Media.

Lester, P., Peterson, K., Reeves, J., Knauss, L., Glover, D., Mogil, C., et al. (2010b). The long war and parental combat deployment: Effects on military children and at-home spouses. Journal of the American Academy of Child and Adolescent Psychiatry, 49, 310-320.

Lester, P., Stein, J. A., Bursch, B., Rice, E., Green, S., Penniman, T., et al. (2010c). Family-based processes associated with adolescent distress, substance use and risky sexual behavior in families affected by maternal HIV. Journal of Clinical Child and Adolescent Psychology, 39, 328-340.

Lester, P., Mogil, C., Saltzman, W., Woodward, K., Nash, W., Leskin, G., et al. (2011a). FOCUS (Families OverComing Under Stress): Implementing family-centered prevention for military families facing wartime deployments and combat operational stress. Military Medicine, 176, 19-25. 
Lester, P., Saltzman, W. R., Woodward, K., Glover, D., Leskin, G. A., Bursch, B., et al. (2011b). Evaluation of a family centered prevention intervention for military children and families facing wartime deployments. American Journal of Public Health. (in press)

Masten, A. S. (2004). Regulatory processes, risk, and resilience in adolescent development. Annals of the New York Academy of Sciences, 1021, 310-319

McCarroll, J. E., Ursano, R. J., Liu, X., Thayer, L. E., Newby, J. H., Norwood, A. E., et al. (2000). Deployment and the probability of spousal aggression by U.S. Army soldiers. Military Medicine, $165,41-44$.

Mrazek, P. J., \& Haggerty, R. J. (1994). Reducing risks for mental disorders: Frontiers for preventive intervention research. Washington, DC: The National Academic Press.

Nachmias, M., Gunnar, M., Mangelsdorf, S., Parritz, R. H., \& Buss, K. (1996). Behavioral inhibition and stress reactivity: The moderating role of attachment security. Child Development, 67, 508-522.

Nash, W. P. (2011). U.S. Marine Corps and Navy combat and operational stress continuum model: A tool for leaders. In E. C. Ritchie (Ed.), Combat and operational behavioral health (pp. 193-214). Washington, DC: Borden Institute Textbook of Military Psychiatry.

National Research Council and Institute of Medicine. (1994). Preventing mental, emotional, and behavioral disorders among young people: Progress and possibilities. Committee on Prevention of Mental Disorders and Substance Abuse among Children, Youth and Families: Research Advances and Promising Interventions. M. E. O'Connell, T. Boat, \& K. E. Warner (Eds.). Board on Children, Youth and Families, Division of Behavioral and Social Sciences and Education. Washington, DC: The National Academies Press.

National Research Council and Institute of Medicine. (2009). Preventing mental, emotional, and behavioral disorders among young people: Progress and possibilities. Committee on Prevention of Mental Disorders and Substance Abuse Among Children, Youth, and Young Adults: Research Advances and Promising Interventions. O'Connell ME, Boat T, and. Warner KE, Editors. Board on Children, Youth, and Families, Division of Behavioral and Social Sciences and Education. Washington, DC: The National Academies Press. [On line] http://www.nap.edu/ catalog.php?record id $=12480$

Office of the Deputy Under Secretary of Defense (Military Community and Family Policy), under contract with ICF International. (2007). Demographics 2007: Profile of the military community. Available at http://www.militaryonesource.com/MOS/ServiceProviders/ 2007DemographicsProfileoftheMilitaryCommuni.aspx.

Palmer, C. (2008). A theory of risk and resilience factors in military families. Military Psychology, 20, 205-217.

Proctor, E. K., Rosen, A., \& Rhee, C. (2002). Outcomes in social work practice. Social Work Research \& Evaluation, 3, 109125.

Rogers, E. M. (1983). Diffusion of innovations (3rd ed.). New York: Free.

Rotheram-Borus, M. J., Lee, M. B., Gwadz, M., \& Draimin, B. (2001). An intervention for parents with AIDS and their adolescent children. American Journal of Public Health, 91, 1294-1302.

Rotheram-Borus, M. J., Lee, M., Lin, Y. Y., \& Lester, P. (2004). Six year intervention outcomes for adolescent children of parents with HIV. Archives of Pediatrics \& Adolescent Medicine, 158, 742-748.

Rotheram-Borus, M. J., Lester, P., Song, J., Lin, Y. Y., Leonard, N. R., \& Beckwith, L. (2006). Intergenerational benefits of family-based HIV interventions. Journal of Consulting and Clinical Psychology, $74,622-627$

Rutter, M. (1985). Resilience in the face of adversity: Protective factors and resistance to psychiatric disorder. British Journal of Psychiatry, 147, 598-611.

Rutter, M., \& Quinton, D. (1984). Parental psychiatric disorder: Effects on children. Psychological Medicine, 14, 853-880.

Ryan, C. E., Epstein, N. B., Keitner, G. I., Miller, I. W., \& Bishop, D. S. (2005). Evaluation and treating families: The McMaster approach. New York: Routledge/Taylor \& Francis Group.

Saltzman, W. R., Babayan, T., Lester, P., Beardslee, W. R., \& Pynoos, R. S. (2009). Family-based treatment for child traumatic stress: A review and report on current innovations. In D. Brom, R. PatHorenczyk, \& J. D. Ford (Eds.), Treating traumatized children: Risk, resilience and recovery (pp. 240-254). New York: Routledge/ Taylor \& Francis Group.

Saltzman, W. R., Lester, P., Beardslee, W., \& Pynoos, R. (2007). FOCUS for Military Families: Individual Family Resiliency Training Manual, 1st Edition (unpublished manual).

Sandler, I. N., Ma, Y., Tein, J. Y., Ayers, T. S., Wolchik, S., Kennedy, C., et al. (2010). Long-term effects of the family bereavement program on multiple indicators of grief in parentally bereaved children and adolescents. Journal of Consulting and Clinical Psychology, 78, 131-143.

Segal, M. W. (1986). The military and the family as greedy institutions. Armed Forces \& Society, 13, 9-38.

Spirito, A., Start, L. J., \& Williams, C. (1988). Development of a brief coping checklist for use with pediatric populations. Journal of Pediatric Psychology, 13, 555-574.

Spoth, R. L., Kavanagh, K., \& Dishion, T. (2002). Family-centered preventive intervention science: Toward benefits to larger populations of children, youth, and families. Prevention Science, $3,145-152$.

Sroufe, L. A. (2005). Attachment and development: A prospective, longitudinal study from birth to adulthood. Attachment and Human Development, 7, 349-367.

Sroufe, L. A., Egeland, B., Carson, E. A., \& Collins, W. A. (2005). The development of the person: The Minnesota study of risk and adaptation from birth to adulthood. New York: Guilford.

U.S. Marine Corps \& U.S. Navy. (2010). Combat and operational stress control, MCRP 6-11C/NTTP 1-15M. Quantico, VA: Marine Corps Combat Development Command.

Werner, E. E. (1993). Risk, resilience, and recovery: Perspectives from the Kauai longitudinal study. Development and Psychopathology, $5,503-515$

Wingood, G. M., \& DiClemente, R. (2006). Enhancing adoption of evidence-based HIV interventions: Promotion of a suite of HIV prevention interventions for African American women. AIDS Education and Prevention, 18, 161-170. 